\title{
Originals
}

\section{A strong correlation between glomerular filtration rate and filtration surface in diabetic nephropathy}

\author{
R. Østerby ${ }^{1}$, H.-H.Parving ${ }^{2,3}$, G. Nyberg ${ }^{5}$, E. Hommel ${ }^{2}$, H. E. Jørgensen ${ }^{4}$, H. Løkkegaard ${ }^{4}$ and C. Svalander $^{6}$ \\ ${ }^{1}$ Electron Microscopic Diabetes Research Laboratory, University Institute of Pathology and 2nd University Clinic of Internal Medicine, \\ Aarhus Kommunehospital, ${ }^{2}$ Hvidore Hospital, Klampenborg, ${ }^{3}$ Steno-Memorial Hospital, Gentofte, ${ }^{4}$ Department of Nephrology, Herlev \\ Hospital, Copenhagen, Denmark, ${ }^{5}$ Department of Nephrology, and ${ }^{6}$ Department of Pathology, Sahlgrenska Sjukhuset, Göteborg, Sweden
}

\begin{abstract}
Summary. Quantitative structural studies were performed in kidney biopsy specimens from 24 long-term Type 1 (insulindependent) diabetic patients with persistent albuminuria due to diabetic glomerulopathy. Ten patients were receiving antihypertensive treatment, and among the remaining patients the mean blood pressure was $142 / 91 \mathrm{~mm} \mathrm{Hg}(\mathrm{SD}=11 / 9)$. The urinary albumin excretion rate showed a range from 100 to $5494 \mu \mathrm{g} / \mathrm{min}$ (geometric mean $688 \mu \mathrm{g} / \mathrm{min}$.) Glomerular filtration rate also showed a wide range, from supranormal to markedly decreased values (128 to $28 \mathrm{ml} \cdot \mathrm{min}^{-1}$. $\left(1.73 \mathrm{~m}^{2}\right)^{-1}$, mean 75$)$. The filtration surface (interface between capillary and urinary space) per total number of nephrons (open + occluded) was estimated by combined lightand electron microscopy. The percentage occluded glomeruli as well as structural quantities in the open glomeruli were taken into account in this estimate. A highly significant correlation was seen between glomerular filtration rate and filtration surface per nephron $\left(r=0.77, p<10^{-4}\right)$. The per-
\end{abstract}

centage occluded glomeruli contributed significantly to the variation in glomerular filtration rate (for this relationship tested separately $r=-0.78, p<10^{-5}$ ). The volume of open glomeruli was even larger than that seen in early diabetic glomerular hypertrophy and tended to increase with the percentage of glomerular closure, indicating that a compensatory hypertrophy might have taken place. In the open glomeruli the filtration surface constituted a smaller percent of total capillary surface (the remaining part facing the mesangial regions) than in early diabetic patients and control subjects.

Our study has demonstrated that reduced glomerular filtration surface is closely associated with reduced glomerular filtration rate in Type 1 diabetic patients with diabetic nephropathy.

Key words: Diabetic glomerulopathy, diabetic nephropathy, glomerular ultrastructure, glomerular filtration rate, stereology.
A large proportion (about 40\%) of Type 1 (insulin-dependent) diabetic patients eventually develop nephropathy [1]. The first sign is the appearance of increased urinary albumin excretion (UAE) persisting in a reasonably well controlled metabolic state [2-4]. This is often accompanied or followed by elevation of blood pressure [5], and predicts, with a high probability, development of decreasing glomerular filtration rate (GFR) [2-4]. Unless some interference occurs - or death from other long-term diabetic manifestations the final outcome is end stage renal failure.

It is generally assumed that the cause of this development is the diabetic glomerulopathy, the renal expression of the generalised microangiopathy. The exact relationship between structure and function at one of the turning points, the transition from normo- to microalbuminuria is not clarified; therefore some confusion has arisen concerning the structural basis of the diabetic nephropathy [6].
The present paper deals with quantitative estimates of glomerular structures in a series of long-term Type 1 diabetic patients with persistent albuminuria due to diabetic glomerulopathy. The aim was to study the relationship between the level of GFR and the relevant structural quantities.

\section{Subjects and methods}

\section{Subjects}

Twenty-four Type 1 diabetic patients with persistent albuminuria were investigated. Clinical data are presented in Table 1. Fourteen subjects had been followed regularly at Steno Memorial Hospital and Hvidøre Hospital, Copenhagen. Kidney biopsies were part of the diagnostic evaluation of the underlying cause of the proteinuric state. All such cases available were included in the present series, if the renal biopsy showed no evidence of kidney disease other than diabetic glomerulopathy. Ten patients had been referred to the department of Nephrology, Sahlgrenska Hospital, Göteborg because of 
Table 1. Clinical data in individual patients

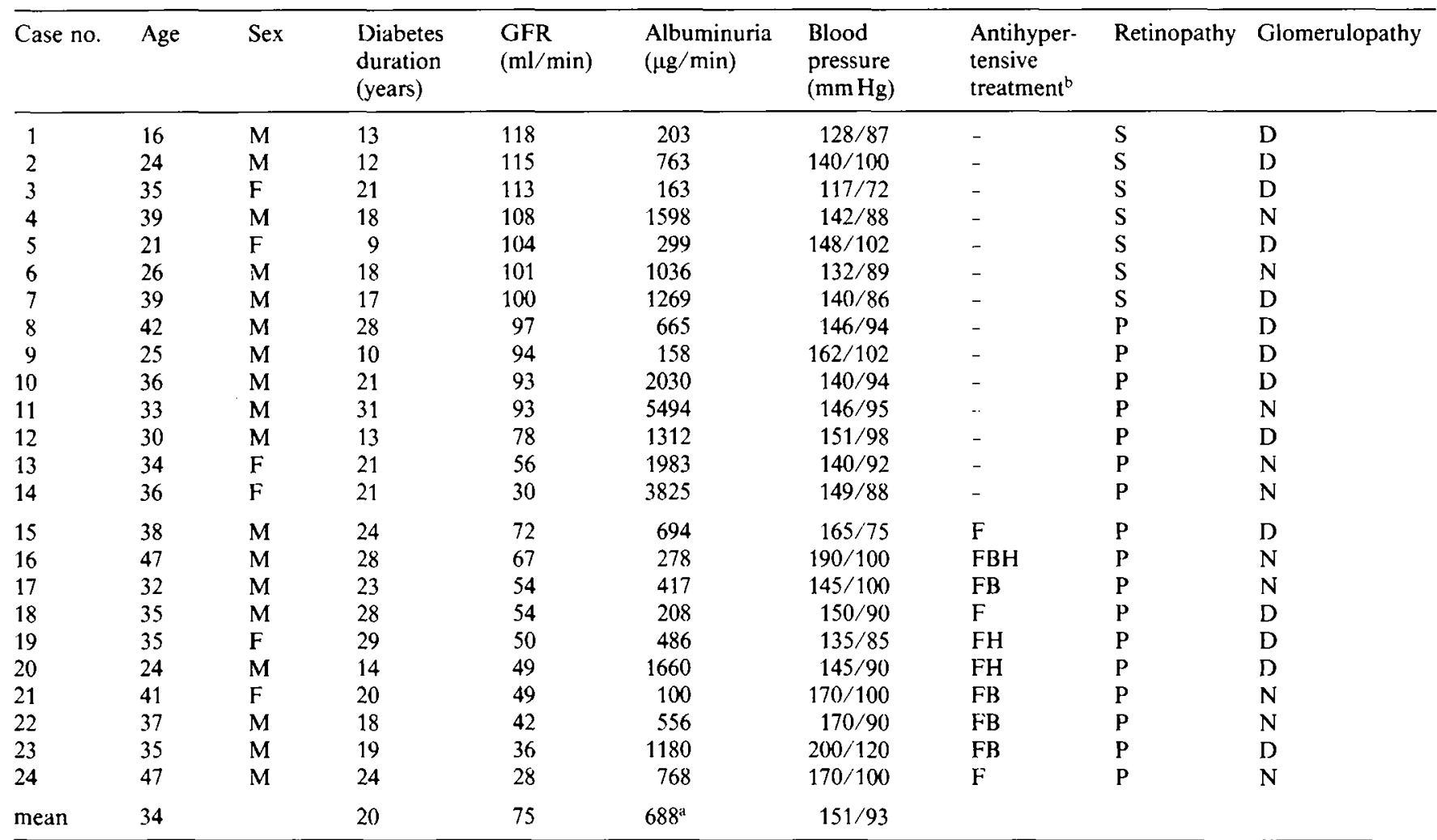

${ }^{a}$ geometric mean; ${ }^{b} \mathrm{~F}$ : furosemide, $\mathrm{H}$ : hydralazin, B: selective $\beta$-blocking agent. The cases no. 15-24 have been on antihypertensive treatment for 1.5-8 years. Results referring to these patients are indicated with black circles in Figures 4-5. Cases number 1-14 did not receive such treatment. Within the two subgroups the patients are arranged in the Table according to GFR-level. Retinopathy was either of simplex (background) or proliferative type. The light microscopic diagnosis was either diffuse (D) or nodular (N) diabetic glomerulopathy

nephropathy with renal insufficiency. They were entering an investigation of diabetic nephropathy, approved by the Committee of Ethics of the University of Göteborg.

Urinary albumin excretion was analysed either by radioimmunoassay [7] on samples collected during the clearance investigations, or by immune electrophoresis [8] on 24-h urine samples. GFR was determined as plasma clearance of ${ }^{51} \mathrm{Cr}$-EDTA [9]. The values uncorrected for body-surface are given in Table 1 for comparison with structural quantities likewise uncorrected. GFR corrected for body surface was in the range from 128 to $28 \mathrm{ml} \cdot \mathrm{min}^{-1} \cdot\left(1.73 \mathrm{~m}^{2}\right)^{-1}$ with a mean of $75 \mathrm{ml} \cdot \min ^{-1} \cdot\left(1.73 \mathrm{~m}^{2}\right)^{-1}$. The time interval between renal function tests and the biopsy was on average 7 weeks (range 1 to 24 weeks).

Ten patients (cases no. 15-24) had hypertension and had received antihypertensive treatment for a period of $1.5-8$ years. As shown in Table 1 treatment was sometimes inadequate. Mean blood pressure in the remaining non-treated cases was $142 / 91 \pm 11 / 9 \mathrm{~mm} \mathrm{Hg}$. All patients had retinopathy, simplex in 10 cases and proliferative in the remaining 14 cases (Table 1 ). The patho-anatomical diagnosis by light microscopy was a typical diabetic glomerulopathy in all cases, 10 of them presenting the nodular type.

\section{Methods}

Percutaneous kidney biopsies were performed using Trucut, Travenol biopsy needle. The tissue was immediately fixed in $2 \%$ glutar-

Fig. 1. One glomerular profile (case no. 23) photographed at light microscopy. The circumscribed minimal convex polygon, used for estimating glomerular volume and representing the reference space common to light and electron microscopy is shown

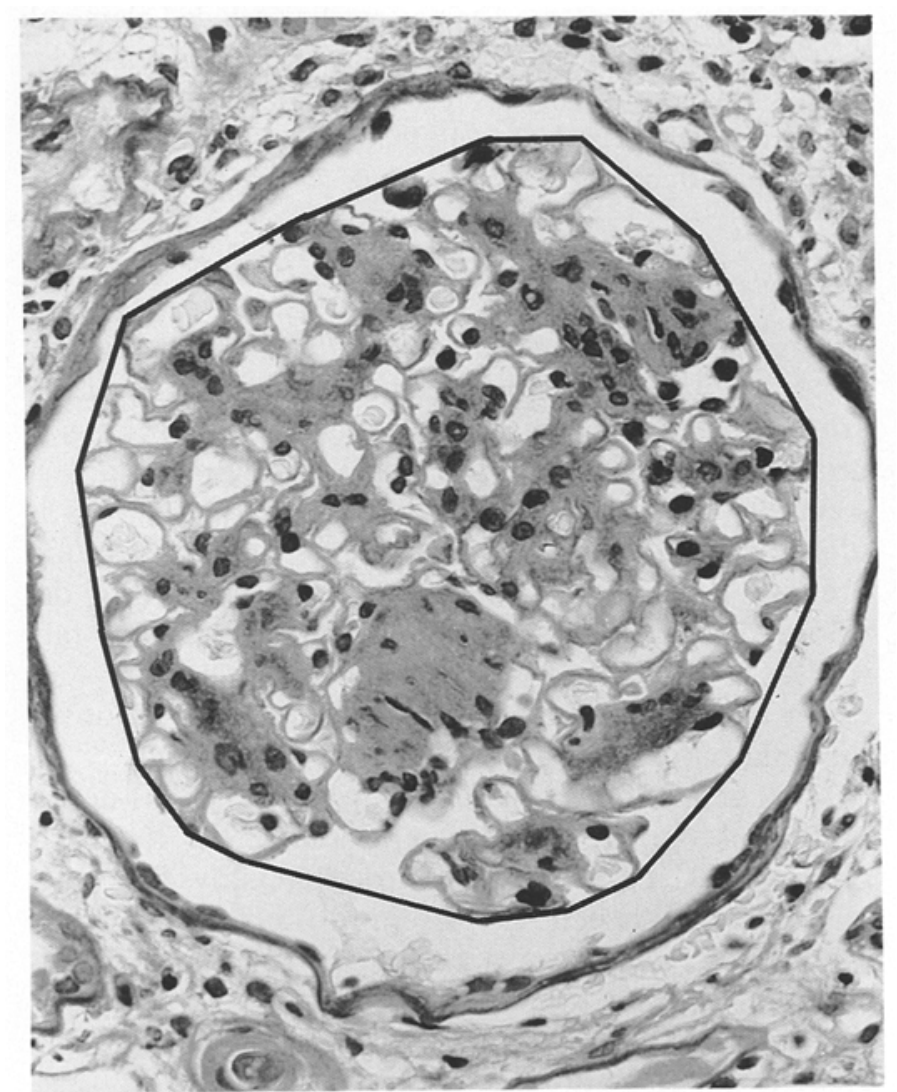



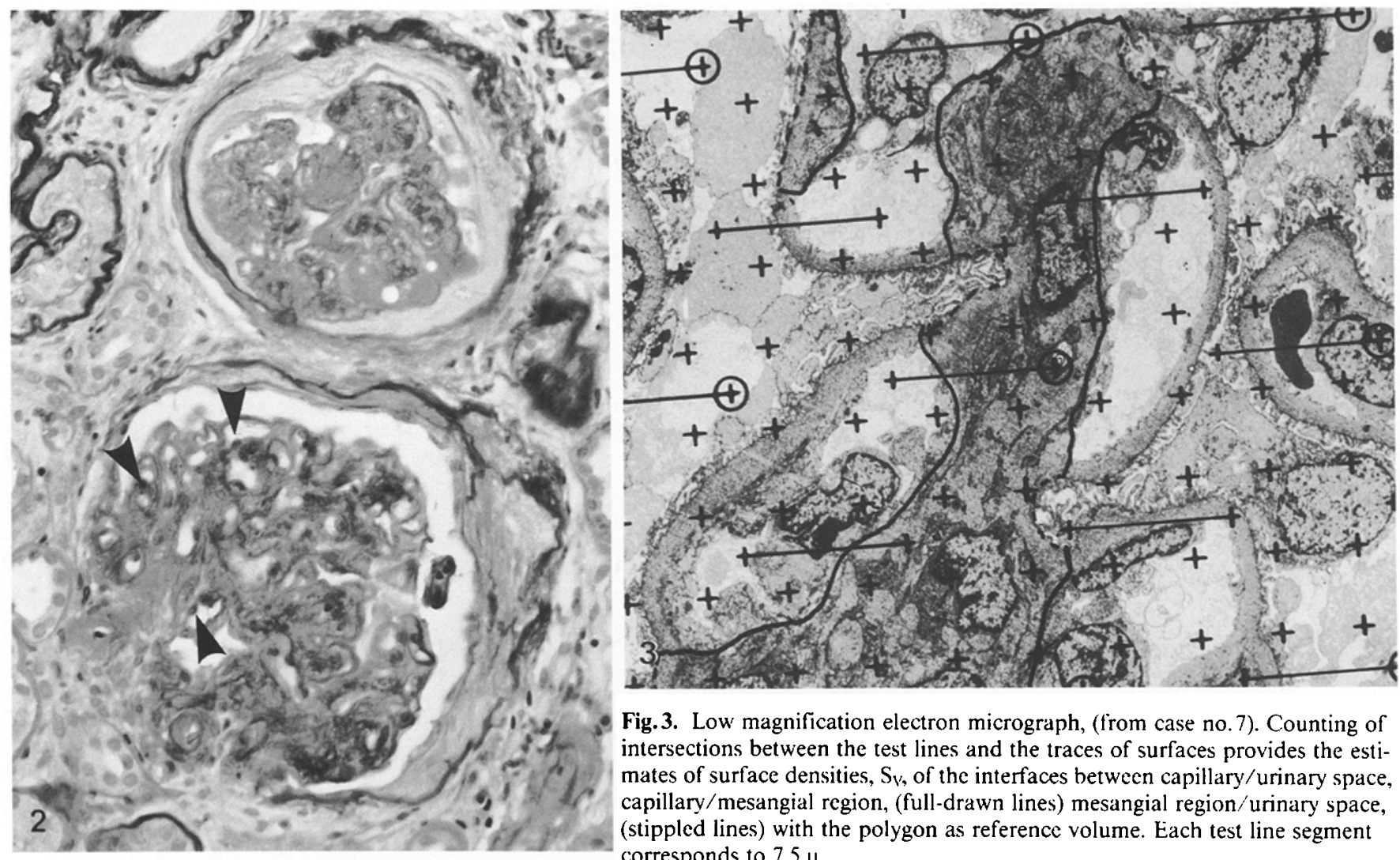

Fig.3. Low magnification electron micrograph, (from case no. 7). Counting of intersections between the test lines and the traces of surfaces provides the estimates of surface densities, $S_{V}$, of the interfaces between capillary/urinary space, capillary/mesangial region, (full-drawn lines) mesangial region/urinary space, (stippled lines) with the polygon as reference volume. Each test line segment corresponds to $7.5 \mu$

Fig. 2. Two glomerular profiles, one bclonging to the category 'occluded', the other termed 'open', since capillary spaces lined by endothelial cells are present (arrows)

aldehyde, and in most cases mailed in the fixative to the laboratory in Aarhus where the further processing and embedding for electron microscopy were done. Part of the biopsy was embedded in paraffin for light microscopy. For the present quantitative study combined light- and electron microscopic measurements were performed as described below.

\section{Light microscopic quantitation}

The paraffin embedded biopsies were cut at a number of levels approximately $50 \mu$ apart. The stained sections were projected to the table using a $16 \times$ Zeiss objective and a projection mirror attached to the monocular tube, providing a magnification of $570 \times$. The area of each glomerular profile was estimated by point counting, the distance between points corresponding to $35 \mu$. Glomerular profiles were delineated by the minimal convex polygon circumscribing the tuft itself, i.e. not including Bowman's space (Fig.1). An independent position of the point grid with respect to the glomerular profiles was secured by entering the section in a systematic way. Each glomerular profile was categorised as being open or occluded. The latter glomeruli were defined as tufts lacking capillary spaces lined by cells (Fig. 2). The mean volumes of open, respectively occluded glomeruli $v(\mathrm{G}, \mathrm{op}), \mathrm{v}(\mathrm{G}, \mathrm{oc})$ were calculated from profile areas applying the method of Weibel and Gomez [10]. The relative number of occluded glomeruli, $\mathrm{N}_{\mathbf{r}}(\mathrm{oc})$, was calculated from the number of profiles, $Q$, of each type, multiplying with the relative probability proportional to the glomerular diameter of hitting the large open/smaller occluded glomeruli, respectively, with the plane of sectioning. As a measure, proportional to linear glomerular size was used $d \sim \sqrt[3]{\bar{v}}$, and the numerical fraction of occluded glomeruli was then estimated by $\mathrm{N}_{\mathrm{N}}(\mathrm{oc})=\frac{\mathrm{Q}(\mathrm{oc}) \cdot \mathrm{d}(\mathrm{op})}{\mathrm{Q}(\mathrm{oc}) \cdot \mathrm{d}(\mathrm{op})+\mathrm{Q}(\mathrm{op}) \cdot \mathrm{d}(\mathrm{oc})}$. The number of profiles quantitated per biopsy was on average 124 with a range of 30 to 243 .

\section{Electron microscopic quantitation}

Three to five glomerular profiles were cut in each case for electron microscopy using a sampling system that secured an unbiased sample of the population of open glomeruli [11], i.e. sampling independent of the histological appearance or glomerular size. The total profile was photographed at $2,300-3,500 \times$ magnification. On the montage the polygon circumscribing the capillary tuft was drawn, providing the reference space common to light- and electron microscopy. The mesangial regions were delineated, marking separately the surface towards capillary (mes/cap) and that towards the urinary space (mes/us). A grid with several densities of test points and tcst lines was superimposed (Fig. 3). Intersections were counted between the test lines and the three subsets of surfaces of the tuft: mes/us, mes/cap, cap/us, the two latter summing up to total capillary surface. The term filtration surface is used for the interface (cap/us) between capillary and urinary space. The standard stereological cstimate of surface density [10], i.e. surface area related to volume of reference space is

$\mathrm{S}_{\mathrm{V}}=2 \times \mathrm{I}_{\mathrm{L}}$

where $I$ is the number of intersections between test-lines and the trace of the surface, and ${ }_{L}$ is total test-line length inside the reference space (the polygon).

Taking the fraction of occluded glomeruli into account an estimate of absolute filtration surface per nephron (i.e. total population of open + occluded corpuscles) is obtained:

$S=S_{v}($ cap $/$ us $) \cdot v(G, o p) \cdot\left(1-N_{i}(o c)\right)$

This estimate of total area of filtration surface per nephron is comparable between patients assuming an equal number of nephrons per kidney. It is the estimate of total filtrations surface which it is possible to derive from the probe of kidney tissue presented by the renal biopsy. 
Table 2. Structural data in individual patients

\begin{tabular}{|c|c|c|c|c|}
\hline $\begin{array}{l}\text { Case } \\
\text { no. }\end{array}$ & $\begin{array}{l}\text { Glomerular } \\
\text { occlusion } \\
(\%)\end{array}$ & $\begin{array}{l}\text { Mean vol- } \\
\text { ume, open } \\
\text { glomeruli } \\
\left(\mathrm{M} \mu^{3}\right)\end{array}$ & $\begin{array}{l}\text { Mean vol- } \\
\text { ume, oc- } \\
\text { cluded glom- } \\
\text { eruli }\left(\mathrm{M} \mu^{3}\right)\end{array}$ & $\begin{array}{l}\text { Filtration sur- } \\
\text { face per neph- } \\
\text { ron }\left(\mathrm{mm}^{2}\right)\end{array}$ \\
\hline 1 & 0 & 1.98 & - & 0.35 \\
\hline 2 & 3 & 2.69 & 1.02 & 0.31 \\
\hline 3 & 24 & 1.83 & 0.49 & 0.22 \\
\hline 4 & 2 & 2.02 & 1.47 & 0.30 \\
\hline 5 & 27 & 2.64 & 0.63 & 0.35 \\
\hline 6 & 4 & 2.79 & 1.49 & 0.36 \\
\hline 7 & 10 & 1.94 & 1.17 & 0.24 \\
\hline 8 & 20 & 2.60 & 0.91 & 0.20 \\
\hline 9 & 15 & 1.54 & 0.39 & 0.22 \\
\hline 10 & 5 & 1.17 & 0.29 & 0.17 \\
\hline 11 & 38 & 2.60 & 0.88 & 0.20 \\
\hline 12 & 4 & 2.00 & 0.83 & 0.25 \\
\hline 13 & 49 & 1.88 & 0.74 & 0.13 \\
\hline 14 & 30 & 2.66 & 1.11 & 0.13 \\
\hline 15 & 27 & 2.37 & 1.11 & 0.16 \\
\hline 16 & 30 & 3.74 & 1.33 & 0.30 \\
\hline 17 & 24 & 2.75 & 1.22 & 0.20 \\
\hline 18 & 36 & 2.11 & 0.73 & 0.19 \\
\hline 19 & 32 & 2.56 & 0.70 & 0.15 \\
\hline 20 & 50 & 1.74 & 1.08 & 0.12 \\
\hline 21 & 42 & 2.43 & 0.83 & 0.07 \\
\hline 22 & 36 & 2.45 & 1.08 & 0.15 \\
\hline 23 & 45 & 2.50 & 1.52 & 0.15 \\
\hline 24 & 67 & 3.94 & 1.91 & 0.12 \\
\hline mean & 26 & 2.37 & 1.00 & 0.21 \\
\hline
\end{tabular}

Mean glomerular volumes are given in million $\mu^{3}\left(\mathrm{M} \mu^{3}\right)$. Filtration surface (last column) is calculated per total number of nephrons (open + occluded)

\section{Statistical analysis}

Correlation analyses were performed by Pearson's product moment correlation coefficient, $r$. A value of $2 p<0.05$ was considered statistically significant.

\section{Results}

Table 2 presents the results of the structural study in individual patients. The relationship between estimate of filtrations surface obtained from the kidney biopsy and the contemporary GFR determination appears in Fig.4. The correlation is statistically significant, $r=0.77,2 p<10^{-4}$. Similarly, a close inverse correlation exists between GFR and the estimate of glomerular occlusion $\left(r=-0.78,2 p<10^{-5}\right)$ (Fig. 5). A negative correlation between size of filtration surface and the duration of diabetes falls just short of statistical significance, $r=-0.39,2 p=0.059$.

It appears from the Table that the mean volume of occluded glomeruli is less than that of the open ones. The open, still functioning glomeruli are in fact larger than in early diabetic glomerular hypertrophy [12].

Correlation analysis of the present series showed that the volume of open glomeruli tends to be larger when an increasing percentage of glomeruli are occluded $(r=0.39,2 p=0.057)$.

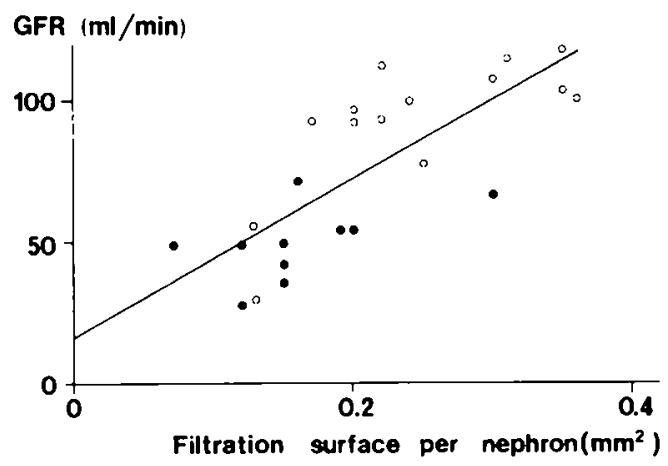

Fig.4. Relationship between glomerular filtration rate (GFR) (uncorrected) and the estimates of filtration surface per nephron. The regression line is shown $\left(r=0.77,2 p<10^{-4}\right)$. Open circles $(O)$ represent cases 1-14 (no antihypertensive treatment), closed circles $(\odot)$ cases 15-24 (antihypertensive treatment)

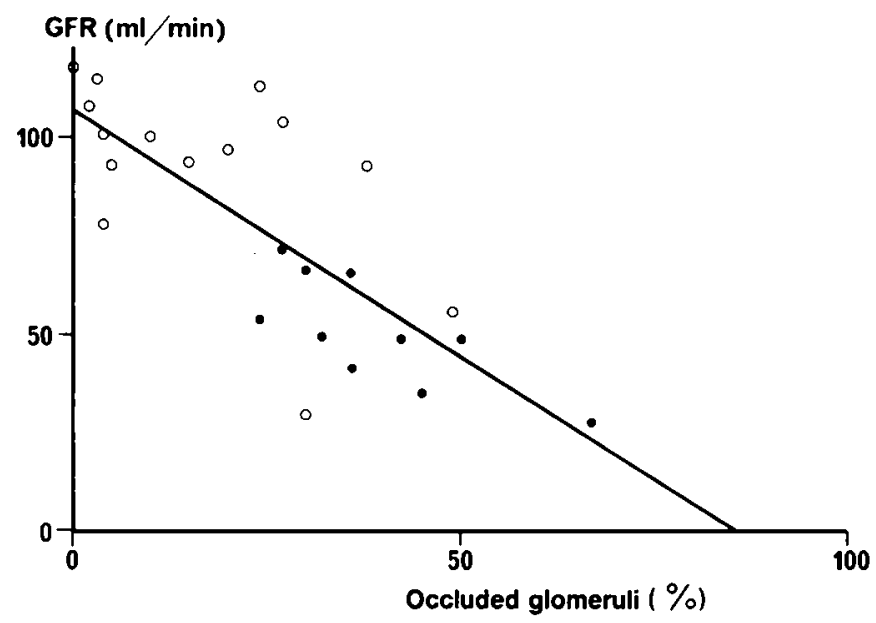

Fig.5. The inverse relationship between GFR and the fraction of glomeruli which is occluded. The regression line is shown, $r=-0.78$, $2 p<10^{-5}$. Symbols as in Figure 4

The filtration surface dealt with above constitutes one part of the total capillary surface, the remaining part being that facing the mesangial regions (cap/mes). The relative contribution of each to total capillary surface is directly derived from the surface densities of the two compartments. In the present series the filtration surface made up on average $57 \%$ of total capillary surface, a fraction which is less than that previously estimated in control subjects $(67 \%)$ and in shortterm diabetic patients $(71 \%)[13]\left(2 p=0.03\right.$ and $<10^{-8}$, respectively).

\section{Discussion}

The level of renal function in terms of GFR was found to relate closely to the structural quantity estimated as total peripheral glomerular capillary surface per nephron in Type 1 diabetic patients with diabetic nephropathy. This result is in complete agreement with recently published data by Ellis and coworkers [13]. Their series 
of 37 diabetic patients comprised a wider range of renal function, 18 of the patients being normoalbuminuric with elevated GFR as judged from creatinine clearance, while 7 patients showed microalbuminuria and only 12 had clinical diabetic nephropathy corresponding to our patients. The authors estimated not only total filtration surface per patient which is comparable to the parameter of the present paper but also filtration surface per glomerulus, referring only to the subset of open tufts. Both estimates showed a positive correlation to the creatinine clearance. However, in advanced glomerulopathy with a large number of glomeruli occluded, filtration surface per open glomerulus is not the relevant parameter to relate to renal function [14]. The positive correlation obtained is most likely due to the fact that the majority of the patients had normo- or microalbuminuria, and thus presumably a low percentage of glomerular occlusion. Most important however, is the relationship between filtration surface per patient and GFR. We have now demonstrated such a relationship in a more homogeneous group of patients, all with clinical diabetic nephropathy and using a more exact measurement of GFR. The two different series together underline the close relationship between the advanced stages of diabetic glomerulopathy and renal functional impairment.

A close correlation between GFR and filtration surface has previously been demonstrated also in early diabetes in the hypertrophy-hyperfunction state when GFR is elevated and the total filtration surface is increased $[15,16]$.

In the interval between these two extremes the diabetic glomerulopathy has developed. The structural hallmark of the glomerulopathy is basement membrane accumulation appearing initially after a few years as basement membrane thickening and later as an accumulation in the expanded mesangial regions $[14,17-19]$. These structural changes develop over a period of years during which they do not have any detectable impact on renal function. In this clinically silent stage GFR usually remains high [20], and also the renal hypertrophy persists [21]. It appears from the data presented by Ellis et al. [13] that there is no tendency to decreasing glomerular volume with increasing duration considering only patients with normo- or microalbuminuria, thereby avoiding to confound with the later appearing compensatory hypertrophy [14].

The total amount of filtration surface available in individual patients depends on the percentage occlusion, the structural composition of open glomeruli and the total number of nephrons. The latter parameter cannot be estimated in biopsy material and comparisons between individuals rest on the assumption of equal numbers. A recent study has demonstrated a very large biological variation in total number of nephrons (Bendtsen and Nyengaard, personal communication), but it is a priori very unlikely to be related to the stage of development of diabetic glomerulopathy so as to interfere with the relationship studied. It is, however, very likely to increase the observed variation between patients in the estimated filtration surface. Another question is whether occluded glomeruli after some time disappear in the sense that that they will not be recognised in the tissue sections. If this is the case it leads to an over-estimation of total filtration surface in the most advanced cases.

It is not possible to determine in exact terms the mechanisms leading to glomerular closure. From the inspection of the histological sections one gets the impression that one process is the "filling up" of the glomerular tuft with solid material, i.e. mesangial regions and thick peripheral basement membrane or, in other words, the end result of the structural changes of the diabetic glomerulopathy. Extra-glomerular factors related to the vessels and/or the interstitum may also play a role since the glomerular occlusion in the longterm diabetic kidney has been shown to occur in stripes perpendicular to the kidney surface [22].

The consequence of glomerular closure, on the other hand, is obvious: an occluded glomerulus does not contribute at all to glomerular filtration. Therefore, it is quite natural that the number of occluded glomeruli bears a very strong influence on the level of GFR as seen in this study. This holds even though the category 'occluded glomeruli' was based upon the appearance of a random profile through that glomerular tuft. In another plane of sectioning functioning capillary loops may have been present, but at any rate they would at most contribute with a very small surface area.

The glomerular occlusion may also have consequences in the neighbouring, open, still-functioning tufts. The very large open glomeruli in the long-term diabetic kidney may well represent a compensatory hypertrophy due to the loss of nephrons, and it is most pronounced in those glomeruli least affected by the glomerulopathy [23].

It has been suggested that the increased work load in the remaining population of glomeruli represents a further insult which may accelerate structural damage [24]. However, if a compensatory hypertrophy takes place at this stage it will provide a preservation of filtration surface for some time, and thereby perhaps all together a longer renal survival [14].

It has been shown that aggressive treatment of the elevated blood pressure is capable of reducing the decline rate in GFR in diabetic nephropathy $[25,26]$; this is so even in more advanced stages of the disease [27, 28]. The mechanisms in the interference of this treatment with either structure or function are unknown, and the present series was not designed to answer these questions.

The structural quantities obtained in the present study are not optimal stereological parameters. Structural quantities relevant for the whole kidney are needed for comparison with renal function tests - but only a kidney biopsy is available. In this sample of tis- 
sue the estimates of number of glomeruli occluded as well as of glomerular size have a rather high imprecision. Irrespective of these reservations as to the methodology, the relationship between function on one hand and the structural estimates on the other stands out quite clearly. It thereby strongly underlines the significance of the diabetic glomerulopathy in determining late functional decline.

Acknowledgments. The very skilful technical assistance by Ms K. Gerlach, Ms A. Larsen and Ms L. Nielsen is gratefully acknowledged. The study was supported by grants from P.Carl Petersen's and Helen and Ejnar Bjornow's Foundation, The Danish Research Council and Århus University.

\section{References}

1. Andersen AR, Christiansen JS, Andersen JK, Kreiner S, Deckert T (1983) Diabetic nephropathy in Type 1 (insulin-dependent) diabetes. An epidemiological study. Diabetologia 25: 496-501

2. Parving H-H, Oxenbøll B, Svendsen PAA, Christensen JS, Andersen AR (1982) Early detection of patients at risk of developing diabetic nephropathy. A longitudinal study of urinary albumin excretion. Acta Endocrinol 100: 550-555

3. Viberti GC, Hill RD, Jarrett RJ, Argyropoulos A, Mahmud U, Keen H (1982) Microalbuminuria as a predictor of clinical nephropathy in insulin-dependent diabetes mellitus. Lancet I: $1430-1432$

4. Mogensen CE, Christensen CK (1984) Predicting diabetic nephropathy in insulin-dependent patients. N Engl J Med 311: 89-93

5. Christensen CK, Mogensen CE (1985) The course of incipient diabetic nephropathy: studies of albumin excretion and blood pressure. Diabetic Medicine 2: 97-102

6. Deckert T, Feldt-Rasmussen B, Mathiesen E, Baker L (1984) Pathogenesis of incipient nephropathy: a hypothesis. Diabetic Nephropathy 3:83-88

7. Miles DW, Mogensen CE, Gundersen HJG (1970) Radioimmunoassay for urinary albumin using a single antibody. Scand $J$ Clin Lab Invest 26:5-11

8. Marcini G, Carbonara AO, Heremans JF (1965) Immunochemical quantitation of antigens by single radial immunodiffusion. Immunochemistry 2: 235-254

9. Bröchner-Mortensen J, Giese J, Rossing N (1969) Renal inulin clearance versus total plasma clearance of ${ }^{51} \mathrm{Cr}$-EDTA. Scand $\mathbf{J}$ Clin Lab Invest 23: 301-305

10. Weibel ER (ed) (1979) Stereological Methods, Vol 1. Practical Methods for Biological Morphometry. Academic Press, London New York Toronto

11. Osterby R, Gundersen HJG (1978) Sampling problems in the kidney. In: Miles RE, Serra J (eds) Lecture notes in biomathematics, Vol 23. Springer, Berlin Heidelberg New York, pp 185-191

12. Osterby R, Gundersen HJG (1975) Glomerular size and structure in diabetes mellitus, Vol 1. Early abnormalities. Diabetologia 11: 225-229

13. Ellis EN, Steffes MW, Goetz FC, Sutherland DER, Mauer SM
(1986) Glomerular filtration surface in type I diabetes mellitus. Kidney Int 29: 889-894

14. Osterby R, Gundersen HJG, Nyberg G, Aurell M (1987) Advanced diabetic glomerulopathy-quantitative structural characterization of the non-occluded glomeruli. Diabetes 36:612-619

15. Kroustrup JP, Gundersen HJG, Østerby R (1977) Glomerular size and structure in diabetes mellitus, Vol 3. Early enlargement of the capillary surface. Diabetologia 13: 207-210

16. Hirose K, Tsuchida H, Østerby R, Gundersen HJG (1980) A strong correlation between glomerular filtration rate and filtration surface in diabetic kidney hyperfunction. Lab Invest 43: 434-437

17. Osterby R (1975) Early phases in the development of diabetic glomerulopathy. A quantitative electron microscopic study. Acta Med Scand [Suppl] 574: 1-85

18. Mauer SM, Steffes MW, Ellis EN, Sutherland DER, Brown DM, Goetz FC (1984) Structural-functional relationship in diabetic nephropathy. J Clin Invest 74: 1143-1155

19. Østerby R, Andersen AR, Gundersen HJG, Jørgensen HE, Mogensen CE, Parving H-H (1984) Quantitative studies of glomerular ultrastructure in juvenile diabetics with incipient nephropathy. Diabetic Nephropathy 3: 95-100

20. Mogensen CE, Østerby R, Gundersen HJG (1979) Early functional and morphologic vascular renal consequences of the diabetic state. Diabetologia 17: 71-76

21. Ellis EN, Steffes MW, Goetz FC, Sutherland DER, Mauer SM (1985) Relationship of renal size to nephropathy in Type 1 (insulin-dependent) diabetes. Diabetologia 28: 12-15

22. Herlyck A, Gundersen HJG, Østerby R (1986) The cortical distribution pattern of diabetic glomerulopathy. Diabetologia 29: $146-150$

23. Gundersen HJG, Østerby R (1977) Glomerular size and structure in diabetes mellitus, Vol 2. Late abnormalities. Diabetologia 13: $43-48$

24. Hostetter TH, Rennke HG, Brenner BM (1982) The case for intrarenal hypertension in the initiation and progression of diabetic and other glomerulopathies. Am J Med 72: 375-380

25. Mogensen CE (1982) Long-term antihypertensive treatment inhibiting progression of diabetic nephropathy. Br Med J 285: 685

26. Parving H-H, Andersen AR, Smidt UM, Svendsen PAA (1983) Early and aggressive antihypertensive treatment reduces the rate of decline in kidney function in diabetic nephropathy. Lancet I: 1175

27. Nyberg G, Blohmé G, Nordèn G (1986) Constant glomerular filtration rate in diabetic nephropathy. Correlation to blood pressure and blood glucose control. Acta Med Scand 219: 67-72

28. Parving H-H, Andersen AR, Smidt U, Hommel E, Mathiesen E, Svendsen PAA (1987) Effect of antihypertensive treatment on kidney function in diabetic nephropathy. $\mathrm{Br}$ Med J 294: 1443-1447

Received: 11 November 1987

and in revised form: 25 February 1988

Dr. R.Østerby

Diabetes Research Laboratory

Bartholin Building

Aarhus University

DK-8000 Aarhus C

Denmark 